Supplement of Atmos. Chem. Phys., 16, 13807-13821, 2016

http://www.atmos-chem-phys.net/16/13807/2016/

doi:10.5194/acp-16-13807-2016-supplement

(C) Author(s) 2016. CC Attribution 3.0 License.

(c) (i)
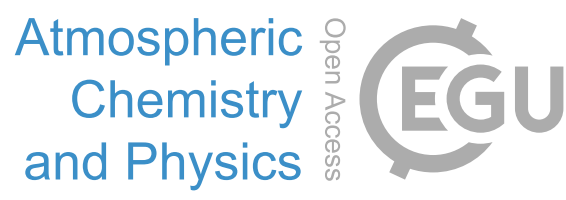

Supplement of

\title{
Speciated atmospheric mercury on haze and non-haze days in an inland city in China
}

\section{Qianqian Hong et al.}

Correspondence to: Zhouqing Xie (zqxie@ustc.edu.cn) and Cheng Liu (chliu81@ustc.edu.cn)

The copyright of individual parts of the supplement might differ from the CC-BY 3.0 licence. 


\section{MAX-DOAS spectral analysis}

The Differential Optical Absorption Spectroscopy (DOAS) was used to retrieve $\mathrm{NO}_{2}$ and $\mathrm{O}_{4}$ differential slant column densities (DSCDs) from the measured scatteredsunlight spectra (Platt, 1994). Each MAX-DOAS scanning cycle consisted of eight elevation viewing angles $\left(2^{\circ}, 3^{\circ}, 6^{\circ}, 8^{\circ}, 10^{\circ}, 20^{\circ}, 30^{\circ}\right.$ and $\left.90^{\circ}\right)$ and lasted about 15 min. The spectra were analyzed using the QDOAS spectral-fitting software suite developed at BIRA-IASB (http://uv-vis.aeronomie.be/software/QDOAS/). $\mathrm{NO}_{2}$ and $\mathrm{O}_{4}$ fitting windows ranged from 338 to370 nm. Trace gas absorption cross sections for $\mathrm{NO}_{2}$ (Vandaele et al., 1998), $\mathrm{O}_{4}\left(\right.$ Hermans et al., 1999), $\mathrm{O}_{3}($ Bogumil et al., 2003),BrO(Fleischmann et al., 2004),HCHO(Meller and Moortgat, 2000) and a Ring spectrum (calculated by QDOAS tools) were included in the spectral fitting analysis. The zenith spectrum of each elevation sequence was used as the reference spectrum. Detailed information about the spectral fitting for $\mathrm{NO}_{2}$ and $\mathrm{O}_{4}$ is listed in Table S2. Figure S6 shows an example of our spectral analysis.

\section{Retrieval description}

In this study, $\mathrm{NO}_{2}$ vertical profiles were retrieved for each MAX-DOAS scanby using the HEIPRO (Heidelberg Profile) profiling tool developed by IUP Heidelberg(Frieß et al., 2006). HEIPRO is based on the optimal estimation method (OEM) (Rodgers, 2000)and includes the SCIATRAN radiative transfer model (RTM) (Rozanov et al., 2005)as aforward model. A two-step approach was implemented in HEIPRO: firstly, since aerosols strongly affect the effective light path in the atmosphere and the optical density of $\mathrm{NO}_{2}$, we need to retrieve aerosol vertical profiles before the retrieval of $\mathrm{NO}_{2}$ vertical profiles. For the aerosol retrieval, $\mathrm{O}_{4}$ DSCDs from different elevations were fed into the aerosol inversion algorithm along with suitable atmospheric vertical pressure, temperature and aerosol a priori profiles. Secondly, measured $\mathrm{NO}_{2} \mathrm{DSCDs}$ and the retrieved aerosol extinctionwere fed into HEIPRO for the radiative transfer calculations.

Figure S7 shows (a) the diurnal cycle of degrees of freedom of signal (DFS) and (b) the errors of the retrieval.DFS corresponds to the number of independent pieces of 
information contained in the measurements,and retrieved DFS should be greater than 0.7 (Wang et al., 2014).In this study, the mean DFS is about 3.72,suggesting that two independent piecesof information can be determined from the measurements.The noise error is related to the propagation of the noise in the measurements intothe retrieval.Thesmoothing error limits the ability of the retrieval to obtainsolutions far from the a priori (Rodgers, 2000). Theaveraging kernels give information on the sensitivity of the retrievals to the $\mathrm{NO}_{2}$ vertical distribution. Figure $\mathrm{S} 8$ (right) shows that the $\mathrm{NO}_{2}$ retrieval is mainly sensitive to the layer close to the surface $(0-220 \mathrm{~m})$.

The retrieved aerosol extinction profile is shown in Figure S4 (left). We use derivative method to calculate the boundary layer height through the aerosol extinction profile (He and Mao, 2005). This method considers the fastest-changing partof the aerosol extinction coefficient as the atmospheric boundary layer height (Wang et al., 2008). The black line in the Figure S4 (left) represents the retrieved atmospheric boundary layer height on 20 November, 2013. 


\section{Calculation of the production rate of $\mathrm{NO}_{2} \mathrm{HgOH}$}

To simplify the solution of the rate equations, we use the steady state approximation to calculate the production rate of $\mathrm{NO}_{2} \mathrm{HgOH}$. Based on $\mathrm{HgOH}$ as an intermediate product, the production rate of $\mathrm{HgOH}$ is equal to the removal rate of $\mathrm{HgOH}$. Thus, we obtain the following equation:

$\mathrm{k}_{1}\left[\mathrm{Hg}^{0}\right][\mathrm{OH}]=\mathrm{k}_{2}[\mathrm{HgOH}]+\mathrm{k}_{3}[\mathrm{HgOH}]\left[\mathrm{NO}_{2}\right]$

From Equation (1), the intermediate $\mathrm{HgOH}$ can be expressed as:

$[\mathrm{HgOH}]=\frac{\mathrm{k}_{1}\left[\mathrm{Hg}^{0}\right][\mathrm{OH}]}{\mathrm{k}_{2}+\mathrm{k}_{3}\left[\mathrm{NO}_{2}\right]}$

The production rate of $\mathrm{NO}_{2} \mathrm{HgOH}$ can be expressed as:

$\frac{\mathrm{d}\left[\mathrm{NO}_{2} \mathrm{HgOH}\right]}{\mathrm{dt}}=\mathrm{k}_{3}[\mathrm{HgOH}]\left[\mathrm{NO}_{2}\right]$

Substituting Eq. (2) into Eq. (3), we obtain Eq. (4) as follows:

$\frac{\mathrm{d}\left[\mathrm{NO}_{2} \mathrm{HgOH}\right]}{d t}=\frac{k_{1} k_{3}\left[\mathrm{Hg}^{0}\right][\mathrm{OH}]\left[\mathrm{NO}_{2}\right]}{k_{2}+k_{3}\left[N \mathrm{NO}_{2}\right]}$

In this case, rate coefficient settings are: $\mathrm{k}_{1}=3.2 \times 10^{-13} \mathrm{~cm}^{3}$ molecule ${ }^{-1} \mathrm{~s}^{-1}, \mathrm{k}_{2}=3.2 \times 10^{3}$ $\mathrm{s}^{-1}$ (Goodsite et al., 2004) and $\mathrm{k}_{3}=2.5 \times 10^{-10} \mathrm{~cm}^{3}$ molecule $\mathrm{s}^{-1}$ (Calvert and Lindberg, 2005). The concentration of the $\mathrm{OH}$ radical is assigned a fixed value consistent with the universal level in the troposphere: $[\mathrm{OH}]=5 \times 10^{6}$ molecule $\mathrm{cm}^{-3}$. $\left[\mathrm{Hg}^{0}\right]$ is fixed at $1.2 \times 10^{7}$ molecule $\mathrm{cm}^{-3}$ (approximates to $4 \mathrm{ng} \mathrm{m}^{-3}$ ). The $\mathrm{NO}_{2}$ concentration is allowed to chang, starting at $0 \mathrm{ppb}$ and increase to several $\mathrm{ppm}\left(1 \mathrm{ppb}=2.46 \times 10^{10}\right.$ molecule $\left.\mathrm{cm}^{-3}\right)$. 


\section{Calculation of the height of atmospheric boundary layer (GB method)}

In addition to estimate the height of the atmospheric boundary layer based on aerosol extinction profile mentioned above, we used the national standard method (GB/T13201-91, referred to as The GB method) of China to calculate as well (Du et al., 2014). The GB method assumes that the thermal condition of the surface layer greatly depend on the heating and cooling degreesof the ground.This method is thus directly based on ground conventional meteorological observation data. In this work, the entire year (from July 2013 to June 2014) of surface meteorological dataacquired by the China Meteorological Administration (CMA) data network was used to calculate the boundary layer height (BLK) in Hefei. Considering the heat and power factors, this method wouldobtain atmospheric stability classification through the solar altitude angle, cloud cover (total cloud cover/low cloud cover) and wind speed. The atmospheric stability is divided, using the Pasquill stability classification method, into 6 levels: strong unstable, unstable, weak unstable, neutral, relatively stable and stable (A, B, C, D, E and F, respectively).

When the atmospheric stability is A, B, C and D, the boundary layer height can be expressed as:

$$
\mathrm{h}=a_{s} \times \frac{U_{10}}{f}
$$

When the atmospheric stability is $\mathrm{E}$ and F, the boundary layer height can be expressed as:

$$
h=b_{s} \times \sqrt{\frac{U_{10}}{f}}
$$

Here $\mathrm{h}$ is the boundary layer height (unit: $\mathrm{m}$ ); $\mathrm{U}_{10}$ is the averaged wind speed at $10 \mathrm{~m}$ altitude (unit: $\mathrm{m} \mathrm{s}^{-1}$, if higher than $6 \mathrm{~m} \mathrm{~s}^{-1}, \mathrm{U}_{10}=6 \mathrm{~m} \mathrm{~s}^{-1}$ ); $\mathrm{a}_{\mathrm{s}}, \mathrm{b}_{\mathrm{s}}$ are the coefficients of the mixing boundary layer (look-up table, which can be found in (Du et al., 2014); $\mathrm{f}$ is the geostrophic parameter, $\mathrm{f}=2 \Omega \sin \Phi, \Omega$ is geostrophic angular velocity, $\Omega=7.29 \times 10^{-5}$ $\operatorname{rad} s^{-1}, \Phi$ is the latitude of observed site (unit: ${ }^{\circ}$ ). Figure S3 shows the diurnal variation of BLK on non-haze and haze days in Hefei. And Figure S4 (right) shows the BLK on 20 November, 2013. 
Table S1. Rate coefficient related to the $\mathrm{Hg}$ reaction with $\mathrm{OH}$ radical in the presence of $\mathrm{NO}_{2}$

\begin{tabular}{lll}
\hline Reaction & Rate constant $(1 \mathrm{~atm}, 298 \mathrm{~K})$ & Reference \\
\hline$(\mathrm{R} 1) \mathrm{Hg}^{0}+\mathrm{OH} \rightarrow \mathrm{HgOH}$ & $\mathrm{k}_{1}=3.2 \times 10^{-13} \mathrm{~cm}^{3}$ molecule $\mathrm{s}^{-1}$ & Goodsite et al.(2004) \\
$(\mathrm{R} 2) \mathrm{HgOH} \rightarrow \mathrm{Hg}^{0}+\mathrm{OH}$ & $\mathrm{k}_{2}=3.2 \times 10^{3} \mathrm{~s}^{-1}$ & Goodiste et al.(2004) \\
$(\mathrm{R} 3) \mathrm{HgOH}+\mathrm{NO}_{2} \rightarrow \mathrm{NO}_{2} \mathrm{HgOH}$ & $\mathrm{k}_{3}=2.5 \times 10^{-10} \mathrm{~cm}^{3}$ molecule $\mathrm{s}^{-1}$ & Calvert and Lindberg et al.(2005) \\
\hline
\end{tabular}

Notes: $\mathrm{k}_{1}$ and $\mathrm{k}_{2}$ refer to the theoretical estimates of Goodsite et al. (2004).

$$
\begin{aligned}
& \mathrm{k}(\mathrm{Hg}+\mathrm{OH} \rightarrow \mathrm{HgOH}, 180-400 \mathrm{~K})=3.2 \times 10^{-13}(\mathrm{~T} / 298 \mathrm{~K})^{-3.06} \mathrm{~cm}^{3} \text { molecule }^{-1} \mathrm{~s}^{-1} \\
& \mathrm{k}(\mathrm{HgOH} \rightarrow \mathrm{Hg}+\mathrm{OH}, 180-400 \mathrm{~K})=2.7 \times 10^{9} \exp (-4061 / \mathrm{T}) \mathrm{s}^{-1}
\end{aligned}
$$

Table S2. DOAS retrieval settings for $\mathrm{NO}_{2}$ and $\mathrm{O}_{4}$.

\begin{tabular}{ll}
\hline \multicolumn{1}{c}{ Parameter } & $\mathrm{NO}_{2}$ and $\mathrm{O}_{4}$ settings \\
\hline Fitting interval (nm) & 338-370 \\
Wavelength calibration & Based on reference SAO solar spectra (Chance and Kurucz, 2010) \\
Polynomial degree & 5 \\
$\mathrm{NO}_{2}$ & Vandaele et al. (1998), 220K, 298K, I0-corrected \\
$\mathrm{O}_{4}$ & Hermans et al. (1999), 296K \\
$\mathrm{O}_{3}$ & Bogumil et al. (2003), 223K, 243K, $\mathrm{I}_{0}$-corrected \\
$\mathrm{HCHO}$ & Meller and Moortgat (2000), 297K \\
$\mathrm{BrO}$ & Fleischmann et al. (2004), 223K \\
$\mathrm{Ring}$ & RING_QDOAS_SAO2010 \\
& Calculated with QDOAS according to Chance and Spurr (1997) \\
\hline
\end{tabular}




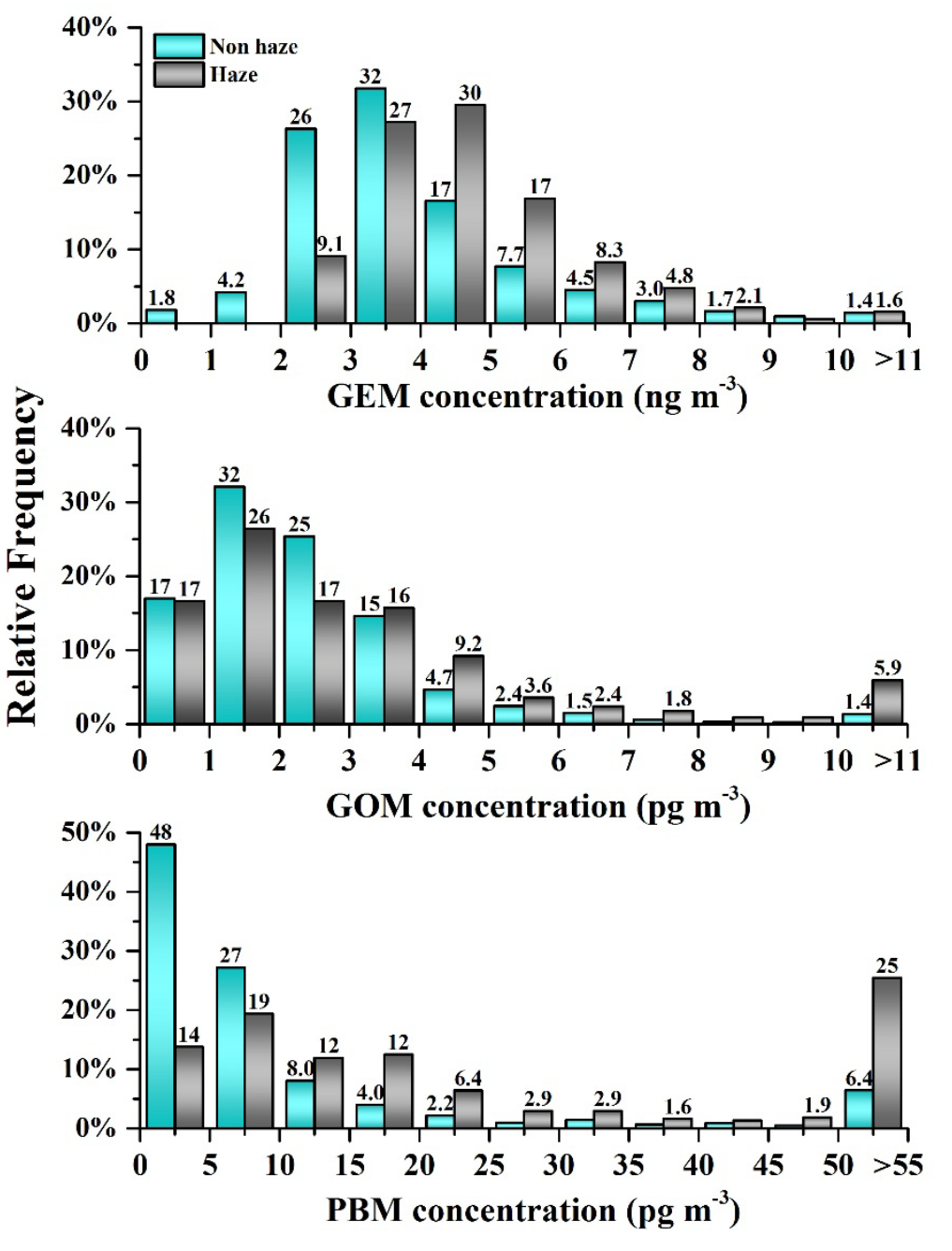

Fig. S1. Frequency distribution of GEM, GOM and PBM on non-haze and haze days. 

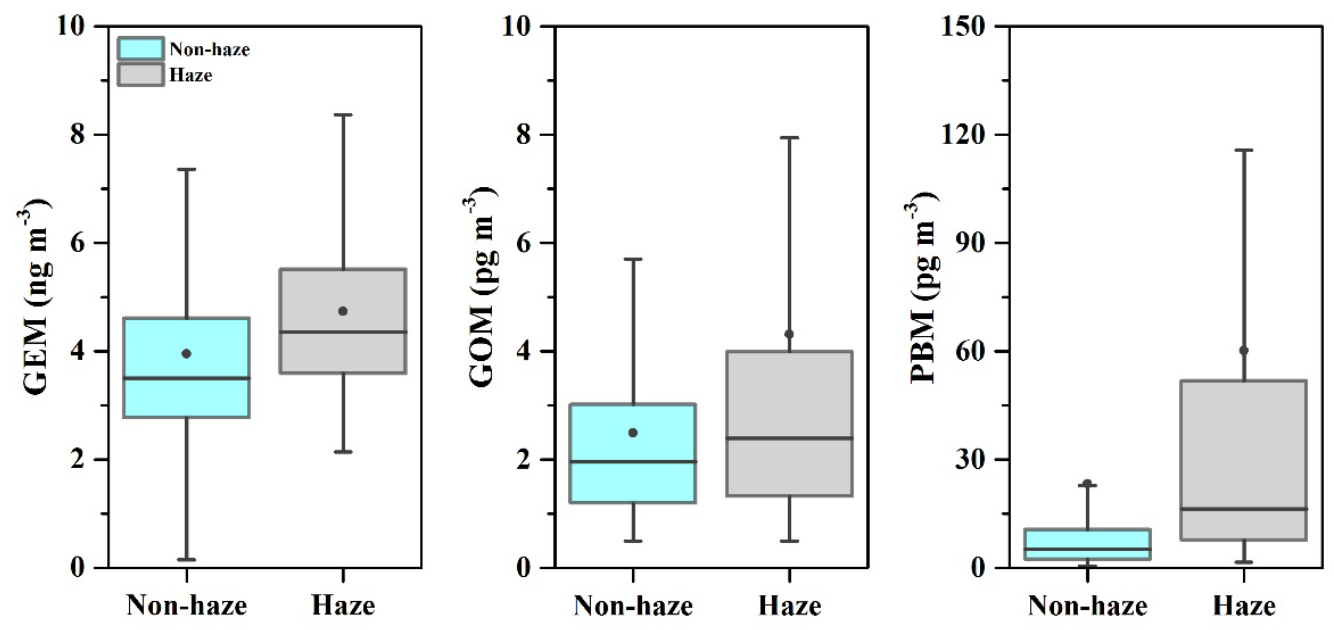

Fig. S2. GEM, GOM and PBM concentrations on non-haze and haze days. The GEM data were at a 5-min resolution, the GOM and PBM data were two-hour averages. Notes: the bottom and top of the box represent the 25th and 75th percentiles, respectively; the line within the box represent the median; the dot represents the mean; the whiskers below and above the box stands for the 10th and 90th percentiles. 


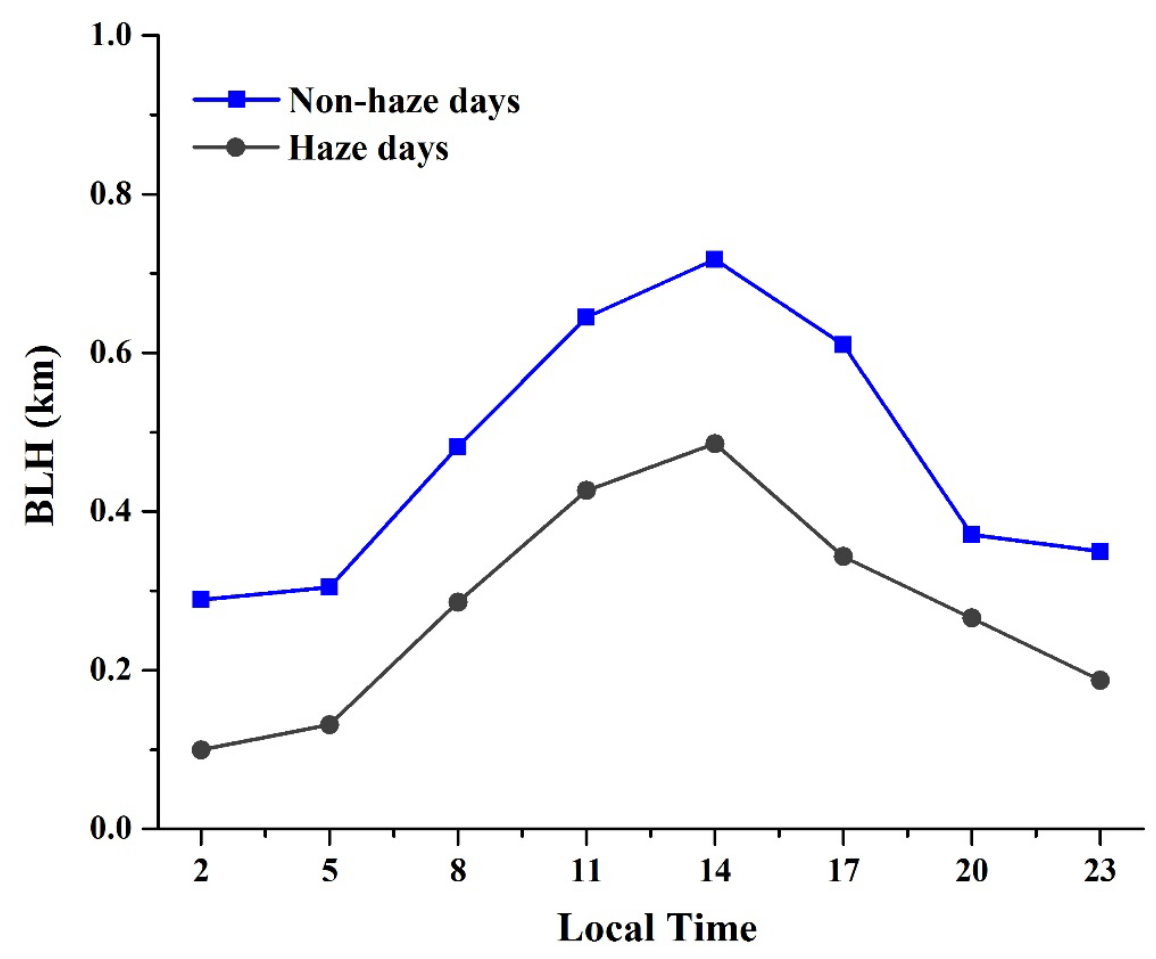

Fig. S3. Diurnal variation of the boundary layer height (BLH) onnon-haze and haze days in Hefei.The atmospheric boundary layer height data were calculated by the GB method as detailed in the text. 

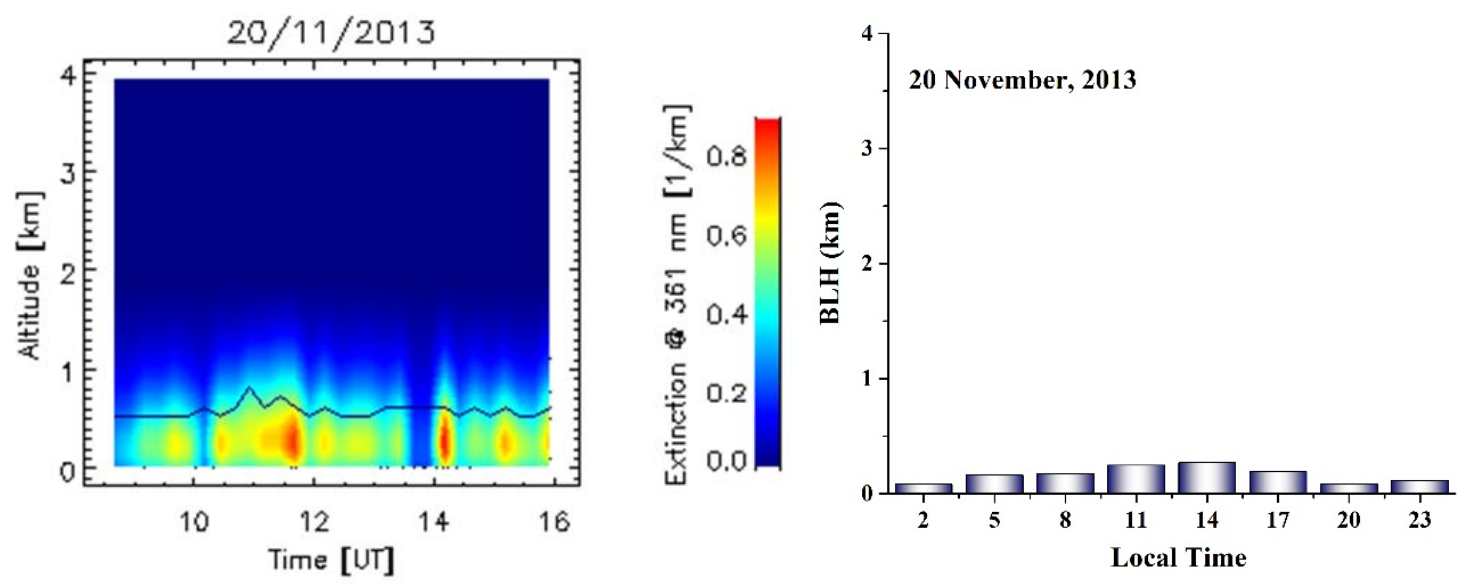

Fig. S4. Retrievedaerosol extinction profile for a case study on 20 November, 2013. The black line represents the height of atmospheric boundary layerduring daytime (left). The atmospheric boudary layer height (BLK) calculated from China Meteorological Administration (CMA) meteorological observation data on 20 November, 2013 (right). 


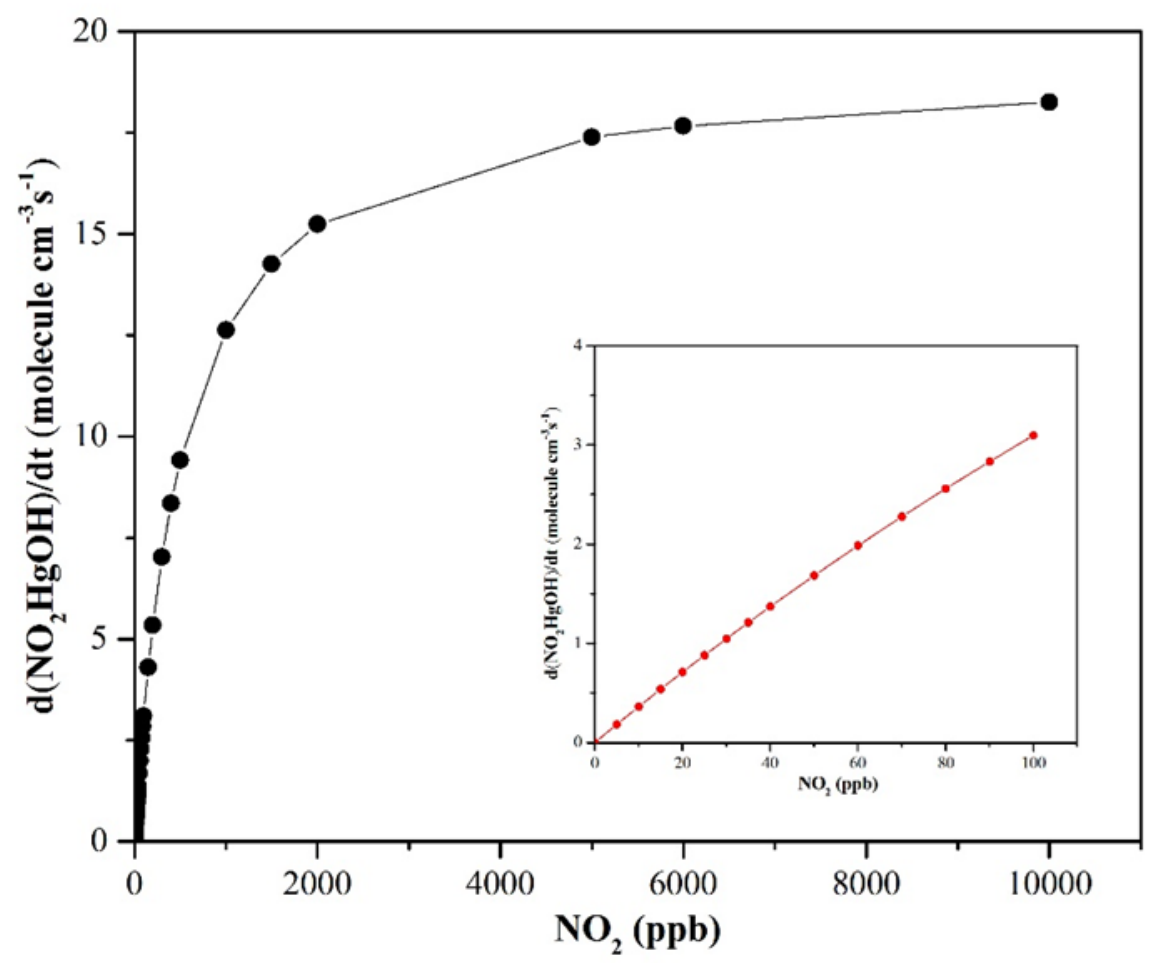

Fig. S5. The production rate of $\mathrm{NO} 2 \mathrm{HgOH}(\mathrm{d}[\mathrm{NO} 2 \mathrm{HgOH}] / \mathrm{dt})$ in response to the change of NO2. 

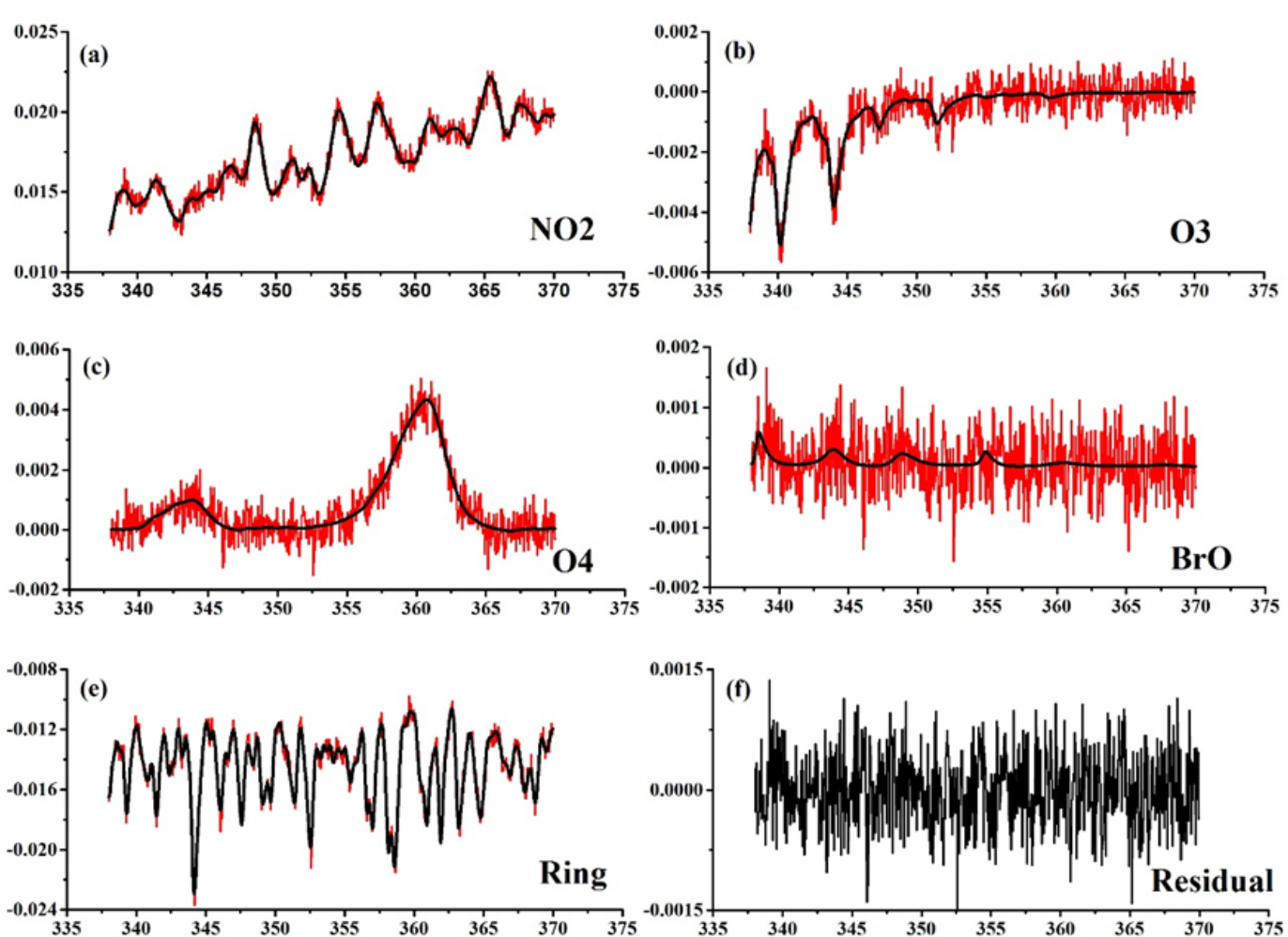

Fig. S6. An Example of the $\mathrm{NO}_{2}$ retrieval (at $30^{\circ}$ elevation angle) taken at 12:25 LT (=UTC+8 hr) on 2 January 2014, with $\mathrm{NO}_{2}$ differential slant column density (DSCD) of $3.58 \times 10^{16}$ molecules $\mathrm{cm}^{-2}$. The black lines represent the reference spectrum scaled to (a) NO2, (b) O3, (c) O4, (d) BrO, (e) Ring absorptions (red lines). The difference between measured spectrum and fit results is shown on (f) residual. 

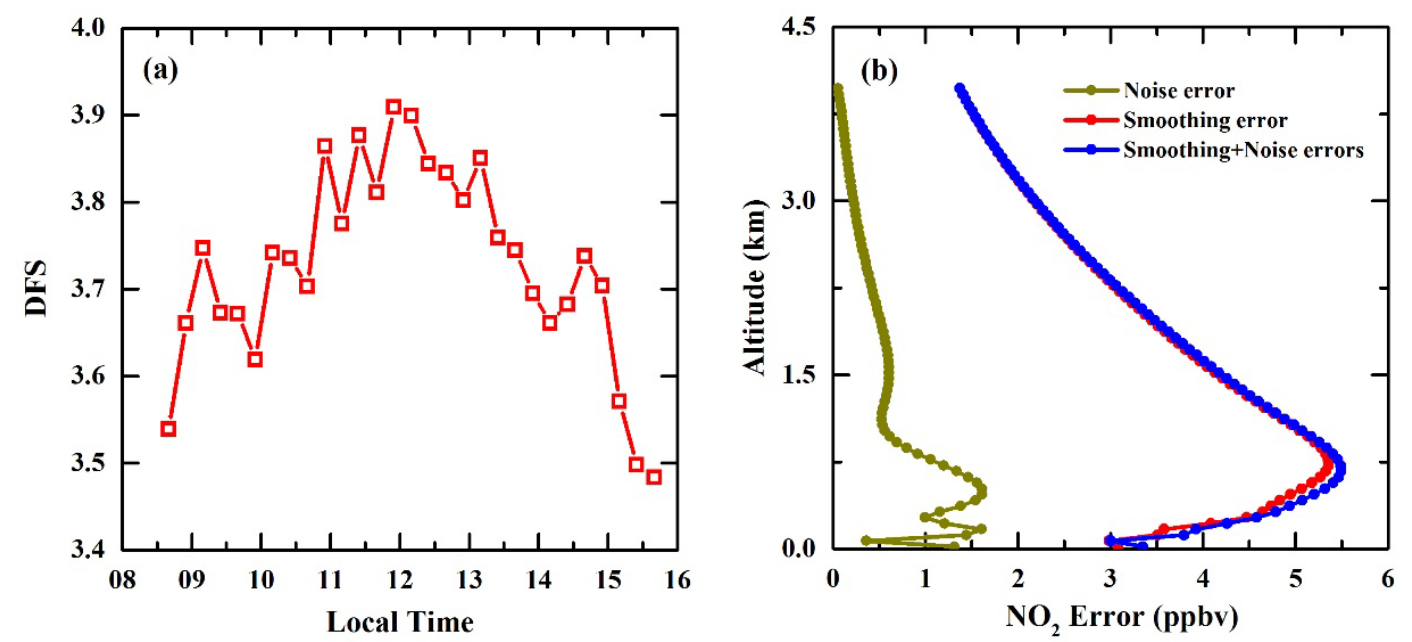

Fig. S7. (a) DFS diurnal cycles corresponding tothe $\mathrm{NO}_{2}$ profile retrievals; (b) Errors of $\mathrm{NO}_{2}$ vertical profile retrieval from MAX-DOAS measurements at Hefei (20 November, 2013 at 10:25LT). 

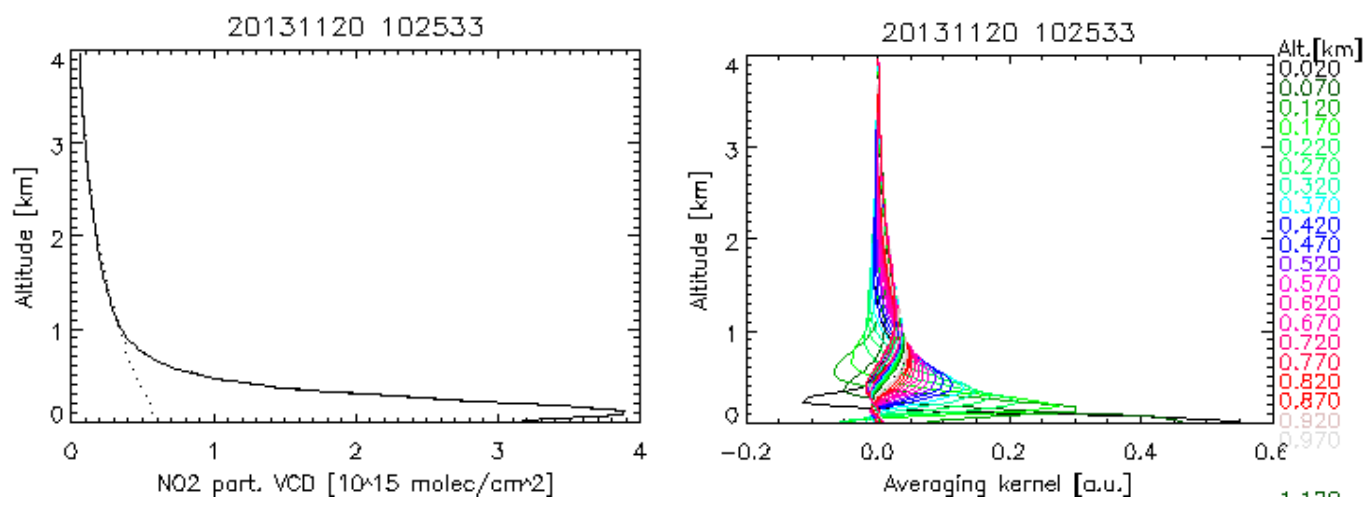

Fig. S8. Example of $\mathrm{NO}_{2}$ vertical retrieved profile and averaging kernels from MAX-DOAS measurements at Hefei (20 November, 2013 at 10:25 local time). 

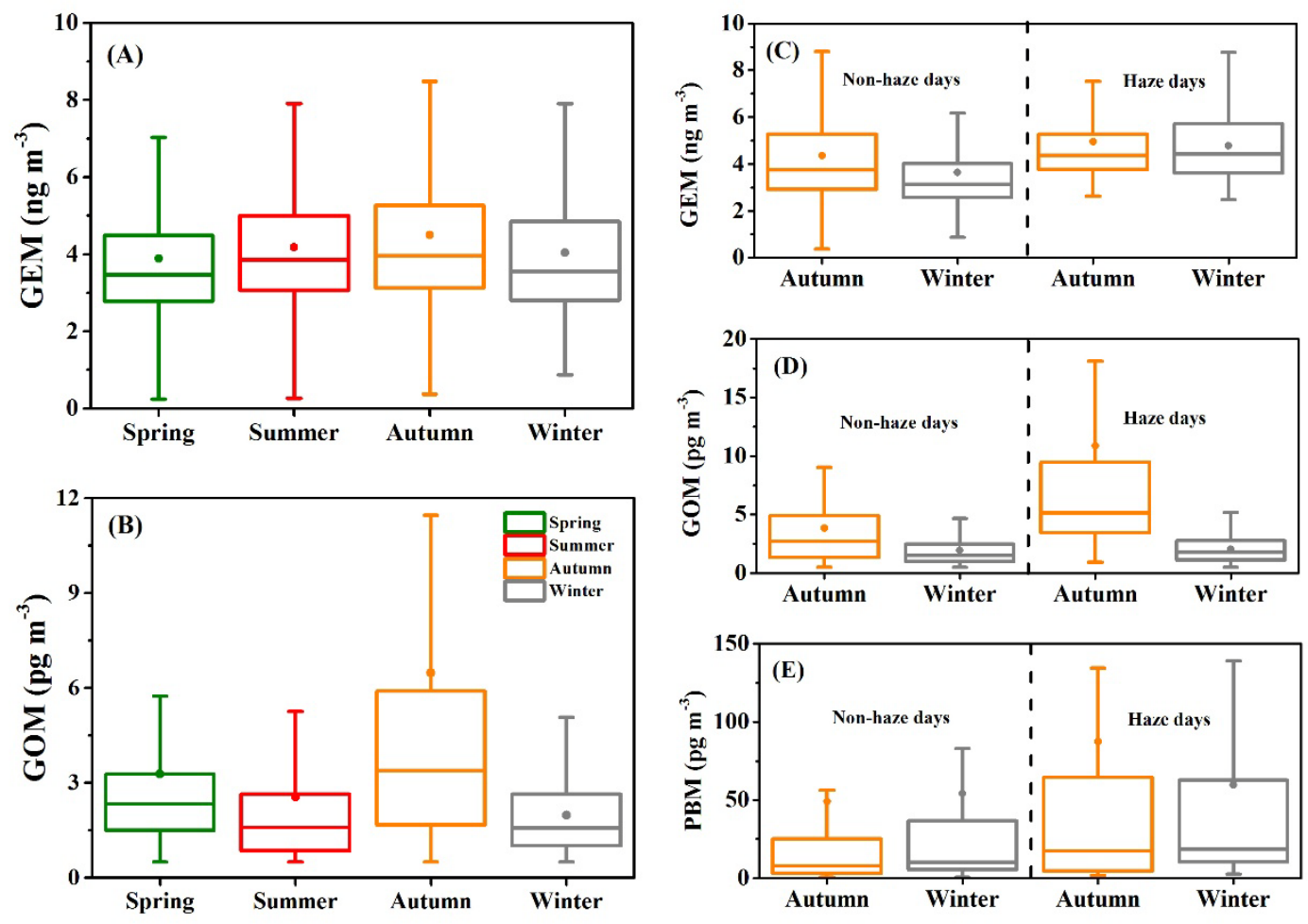

Fig. S9. Seasonal variation of (A) GEM, (B) GOM and (C\&D) PBM concentrations in ambient air at Hefei, Science Island. Notes: the bottom and top of the box represent the 25th and 75th percentiles, respectively; the line within the box represent the median; the dot represents the mean; the whiskers below and above the box stands for the 10th and 90th percentiles. 


\section{References}

Bogumil, K., Orphal, J., Homann, T., Voigt, S., Spietz, P., Fleischmann, O., Vogel, A., Hartmann, M., Kromminga, H., and Bovensmann, H.: Measurements of molecular absorption spectra with the SCIAMACHY pre-flight model: instrument characterization and reference data for atmospheric remote-sensing in the 230-2380 nm region, Journal of Photochemistry and Photobiology A: Chemistry, 157, 167-184, 2003.

Calvert, J. G., and Lindberg, S. E.: Mechanisms of mercury removal by $\mathrm{O}_{3}$ and $\mathrm{OH}$ in the atmosphere, Atmospheric Environment, 39, 3355-3367, 2005.

Chance, K., and Kurucz, R.: An improved high-resolution solar reference spectrum for earth's atmosphere measurements in the ultraviolet, visible, and near infrared, Journal of quantitative spectroscopy and radiative transfer, 111, 1289-1295, 2010.

Du, C., Tang, X., Li, X., Chen, C., Peng, Y., Dong, Y., and Dong, Z.: Calculations of Planetary Boundary Layer Height and Its Relationship with Particle Size Concentration in Xi'an City, Plateau Meteorology, 33, 1383-1392, 2014.

Fleischmann, O. C., Hartmann, M., Burrows, J. P., and Orphal, J.: New ultraviolet absorption cross-sections of $\mathrm{BrO}$ at atmospheric temperatures measured by time-windowing Fourier transform spectroscopy, Journal of Photochemistry and Photobiology A: Chemistry, 168, 117-132, 2004.

Frieß, U., Monks, P., Remedios, J., Rozanov, A., Sinreich, R., Wagner, T., and Platt, U.: MAX - DOAS O4 measurements: A new technique to derive information on atmospheric aerosols: 2. Modeling studies, Journal of Geophysical Research: Atmospheres (1984-2012), 111, 2006.

Goodsite, M. E., Plane, J., and Skov, H.: A theoretical study of the oxidation of $\mathrm{Hg}^{0}$ to $\mathrm{HgBr}_{2}$ in the troposphere, Environmental science \& technology, 38, 1772-1776, 2004.

He, Q., and Mao, J.: Observation of urban mixed layer at Beijing using a micro pulse Lidar, Acta Meteorologica Sinica, 63, 374-384, 2005.

Hermans, C., Vandaele, A. C., Carleer, M., Fally, S., Colin, R., Jenouvrier, A., Coquart, B., and Mérienne, M.-F.: Absorption cross-sections of atmospheric constituents: 
$\mathrm{NO}_{2}, \mathrm{O}_{2}$, and $\mathrm{H}_{2} \mathrm{O}$, Environmental Science and Pollution Research, 6, 151-158, 1999.

Meller, R., and Moortgat, G. K.: Temperature dependence of the absorption cross sections of formaldehyde between 223 and $323 \mathrm{~K}$ in the wavelength range 225-375 nm, Journal of Geophysical Research: Atmospheres, 105, 7089-7101, 2000.

Platt, U.: Differential optical absorption spectroscopy (DOAS), Air monitoring by spectroscopic technique, 127, 27-84, 1994.

Rodgers, C. D.: Inverse methods for atmospheric sounding: theory and practice, World scientific, 2000.

Rozanov, A., Rozanov, V., Buchwitz, M., Kokhanovsky, A., and Burrows, J.: SCIATRAN 2.0-A new radiative transfer model for geophysical applications in the 175-2400nm spectral region, Advances in Space Research, 36, 1015-1019, 2005.

Vandaele, A. C., Hermans, C., Simon, P. C., Carleer, M., Colin, R., Fally, S., Merienne, M.-F., Jenouvrier, A., and Coquart, B.: Measurements of the NO 2 absorption cross-section from $42000 \mathrm{~cm}^{-1}$ to $10000 \mathrm{~cm}^{-1}(238-1000 \mathrm{~nm})$ at $220 \mathrm{~K}$ and $294 \mathrm{~K}$, Journal of Quantitative Spectroscopy and Radiative Transfer, 59, 171-184, 1998.

Wang, T., Hendrick, F., Wang, P., Tang, G., Clémer, K., Yu, H., Fayt, C., Hermans, C., Gielen, C., and Müller, J.-F.: Evaluation of tropospheric $\mathrm{SO}_{2}$ retrieved from MAX-DOAS measurements in Xianghe, China, Atmospheric Chemistry and Physics, 14, 11149-11164, 2014.

Wang, Z., Li, J., Zhong, Z., Liu, D., and Zhou, J.: Lidar exploration of atmospheric boundary layer over downtown of Beijing in summer, Journal of Applied Optics, 29, 96-100, 2008. 